\title{
Extension Block Technique in Management of Mallet Finger
}

\section{Asem Elsayd Gomaa Ibrahim ${ }^{1}$ M.B.B.Ch., Ahmed Shamma ${ }^{1, *}$ MD., Tharwat Abd Elghany ${ }^{1}$ MD.}

\section{* Corresponding Author: \\ Ahmed Shamma \\ ahmedshamma10@icloud.com}

Received for publication March 21, 2021; Accepted April 29, 2021; Published online April 29, 2021.

Copyright 2020 The Authors published by Al-Azhar University, Faculty of Medicine, Cairo, Egypt. All rights reserved. This an openaccess article distributed under the legal terms, where it is permissible to download and share the work provided it is properly cited. The work cannot be changed in any way or used commercially.

doi: $10.21608 /$ aimj.2021.66075.1427

${ }^{1}$ Department of Orthopedic Surgery, Faculty of Medicine, Al-Azhar University, Egypt

\begin{abstract}
Background: Mallet finger is one of the most frequent fingertip injuries that is made by trauma to the terminal inserting of the extensor digitorum tendons. It frequently happens throughout sport activity, while it could as well happen throughout every day activity.

Aim of the work: to evaluate the functional outcome of the extension block fixation of mallet fructure.

Methods: Prospective randomized study. The study had been carried out in orthopedic Surgery departments in Al-Azhar University (Cairo). This study had been conducted on 30 patients of both sex and age ranging between 20 and 50 -yrs old.

Result: IIB was the predominant classification in $63.3 \%$ of the patients, IIC was found in $26.7 \%$, IB was found in $6.7 \%$ and only one patient was IC. The mean operative time was $35.72 \pm 10.09 \mathrm{~min}$ and mean hospital time $1.19 \pm 0.349$ day. Regarding outcomes, 10 (33.3\%) patients were excellent, 16 (53.3\%) patients were good, $3(10 \%)$ patients were fair and 1 (3.3\%) case was poor.

Conclusion: Extension block pinning is a simple and effective treating modality for mallet fractures when performed correctly. It provides excellent functional outcome in acute and sub-acute presentations. It also gives the advantage of treating the fracture as a day care procedure with minimal instruments and no post-operative scars.

Keywords: Extension Block Pinning, Mallet Finger, Treatment, Prospective, Trauma.
\end{abstract}

Disclosure: The authors have no financial interest to declare in relation to the content of this article. The Article Processing Charge was paid for by the authors.

Authorship: All authors have a substantial contribution to the article.

\section{INTRODUCTION}

Mallet injuries are disturbances of the termina $\mathrm{l}$ extensor tendons, from the base of the distal phalanx and they could arise without or with a bony fragmentation. ${ }^{1}$

This type of disruptions may cause a characteristically flexion deformation of the distal inter phalangeal (DIP) joints ${ }^{2}$ Fractures of the distal phalanx happens in 25 percent of mallet traumatic injuries. If the injury is accompanied with bony fragments, it'll be defined as a "Mallet Fracture". These fractures frequently are because of axial loading at the tip of the extended finger as they arise while attempting to capture a ball. ${ }^{4}$ Researches have proven that traditional management gives adequate outcomes in patients with pure extensor tendons avulsion or fractures avulsion of lesser than one third of the distal phalanx.

Some researchers suggested that non-surgical managements of those injuries irrespective of the fragment size of the fracture, the fracture dislocation degree, or the existence of joint subluxation and different recommend surgical interventions for avulsion fracture including greater than one-third of the articular superficial, for permanent subluxation or fragment dislocation that can't be appropriately decreased by complete extension of the DIP joints in splint. They consider that articular inconsistency ultimately will cause symptomatic

Arthritis, extensor lagging or deformation and hence suggest effective treatment to repair the joint integrity. ${ }^{5}$ Many operative strategies for treatment mallet fracture and their complications were defined. Kang et al. concluded that $41 \%$ of operative treatment of mallet fracture advanced post-operative complications like recurrent extension delays, permanent nail deformations, skin necrosis, pin track infections and osteomyelitis

To reduce those complications, percutaneous techniques have recommended by some researchers. ${ }^{6}$

The current work aimed to present the outcomes of the extension block fixations procedure that was initially defined by Ishiguro.

\section{SUBJECTS AND METHODS}

Prospective randomized study. The study had been carried out in orthopedic Surgery departments in AlAzhar University (Cairo). This study had been conducted on 30 patients of both sex and age ranging between 20 and 50-yrs. Inclusion criteria: Participation of greater than 30 percent of articular 
superficial of the distal phalanx, closed fracture and fragmentation absence. Exclusion criteria: Open fractures and chronic mallet fingers.

All cases included in the current work were exposed to the next:

Patient's data had been collected from the hospital data and connection with them had been through phone calling and hospitals follow up visits. Patients had been subjected to clinical and radiological examination including:

Detailed history taking including: Cases' ages and sex, occupation, finger affected, time of trauma, mood of trauma, medical comorbidities as (DM, Rheumatoid...etc.) and past history of previous operative procedure

Careful medical examinations: General: pressure of the blood, pulse, cardio-vascular, neurological and respiration evaluation. Local: Inspection: for deformations, oedema, skin conditions, wounds, palpation: for sensitivity and range of motion.

Investigations: Complete blood count (CBC) and I.N.R.

Operative procedure: Afterward the digit was properly anesthetized by a digital block; the DIP joint was extremely stretched. A $0.12 \mathrm{~cm} \mathrm{~K}$ wire was presented beneath fluoroscopic controlling via the extensor tendons at $45^{\circ}$ angle into the central phalanx, $0.1-0.2 \mathrm{~cm}$ dorsal and proximal to the fracture fragments. The wire delivers an extending block for the bony fragments when the DIP joints were stretched. After the fragments have been decreased, another $1.2 \mathrm{~mm} \mathrm{~K}$ wire has been located longitudinally from distal to proximal through the DIP joint to preserve extensions and decrease. The K-wires have been cut and soft covering was applied. A post-operative volar DIP extending splint has been located to support the wire and the finger. The case was recommended to preserve their digits dry. Pin care was maintained with saline solution twice a day. Cases were permitted PIP and MP joints motions post-operatively. The K-wires have been detached afterward 4 to 6 -wks after there was radiological confirmation of fracture healing with no local anaesthesia beneath sterile condition as an Outpatient. Apalmar splint was used at night to fix the distal interphalangeal joint for 14-days in average. ${ }^{7}$

Postoperative caring: Nonsteroidal anti-inflammatory medication, antibiotics by oral amoxicillin-clavulanic acid for 10 days and plain X-ray AP, lateral

Post operation follow up: All patients were tailed for 3-mths postoperatively

Data was collected as regards: Operative time, postoperative hospitalization, and patient satisfaction, early post-operative complication as skin necrosis and pin track infection. Late complications as recurrent extending delays, lasting nail deformation and osteomyelitis.

Administrative considerations: An Official permission was obtained from Al-Azhar University University Hospital. An official permission was obtained from the Orthopedics department.
Data management and Statistical Analysis: The collected data was analyzed via SPSS-20 (Statistical Package for the Social Sciences). For significance testing (Chi square, Kruskal-Wallis, logistic regression analyzing, Wilcoxon's, and Spearman's correlation) tests have been employed. Data were introduced and appropriate test has been made in accordance to the kind of data (parametric and nonparametric). P-value lesser than 0.05 (5\%) was taken in to consideration to be significant statistically.

\section{RESULTS}

The cases ages ranging from 22 to 50 -yrs with mean $44.67-y r s$, the mainstream of the cases were men by $60 \%$. (Table 1)

$50 \%$ of the patients came in less than a week since fracture, $30 \%$ of the patients came in the same day of the fracture while $20 \%$ of the patients came after a week. (Table 2)

IIB was the predominant classification in $63.3 \%$ of the patients, IIC was found in $26.7 \%$, IB was found in $6.7 \%$ and only one patient was IC. (Table 3)

The mean operative time was $10.09 \pm 35.0 \mathrm{~min}$ and mean hospital time $1.19 \pm 0.349$ day. (Table 4)

Regarding outcomes, 10 (33.3\%) patients were excellent, 16 (53.3\%) patients were good, 3 (10\%) patients were fair and 1 (3.3\%) case was poor. (Table 6)

Regarding complications, 3 (10\%) patients have superficial infection, one (5.6\%) case have skin necrosis and one (5.6\%) patient have pin track infection. No patients reported complications, such as non-union, malunion, dislocation, osteomyelitis, osteoarthritis of DIP joint, nail deformities and dorsal tenderness. (Table 7)

\begin{tabular}{|c|c|c|}
\hline \multicolumn{2}{|c|}{ Variable } & $\begin{array}{l}\text { The studied population } \\
(\mathrm{N}=30)\end{array}$ \\
\hline \multicolumn{2}{|c|}{$\begin{array}{l}\text { Age (yrs) } \\
\text { Mean } \pm \text { SD } \\
\text { Range }\end{array}$} & $\begin{array}{l}64.67 \pm 8.52 \\
22-50\end{array}$ \\
\hline \multirow{2}{*}{ Sex } & Male & 18 (60\%) \\
\hline & Female & $12(40 \%)$ \\
\hline
\end{tabular}

Table 1: Demographical info of the cases involved in the study

\begin{tabular}{|c|c|c|}
\hline \multirow{2}{*}{\multicolumn{2}{|c|}{\begin{tabular}{|l} 
\\
Time since fracture (days) \\
Mean \pm SD
\end{tabular}}} & $\begin{array}{l}\text { The studied } \\
\text { patients }(\mathrm{N}=30)\end{array}$ \\
\hline & & $3.81 \pm 3.02$ \\
\hline \multirow{3}{*}{$\begin{array}{l}\text { Time since } \\
\text { fracture }\end{array}$} & Same day & $9(30 \%)$ \\
\hline & $<$ week & $15(50 \%)$ \\
\hline & $\geq$ week & $6(20 \%)$ \\
\hline
\end{tabular}

Table 2: Time since fractures of the studied patients 


\begin{tabular}{|c|c|}
\hline & $\begin{array}{c}\text { The studied population } \\
(\mathrm{N}=30)\end{array}$ \\
\hline \hline IB & $2(6.7 \%)$ \\
\hline IIB & $19(63.3 \%)$ \\
\hline IC & $1(3.3 \%)$ \\
\hline IIC & $8(26.7 \%)$ \\
\hline
\end{tabular}

Table 3: Wehbe and Schneider sorting of mallet fractures of the studied patients

\begin{tabular}{|l|l|}
\hline & $\begin{array}{l}\text { The studied patients } \\
(\mathrm{N}=30)\end{array}$ \\
\hline \hline $\begin{array}{l}\text { Operation time (mins) } \\
\text { Mean } \pm \text { SD }\end{array}$ & $35.0 \pm 10.09$ \\
\hline $\begin{array}{l}\text { Hospital stay (days) } \\
\text { Mean } \pm \text { SD }\end{array}$ & $1.19 \pm 0.349$ \\
\hline
\end{tabular}

Table 4: Operative time and hospital stay of the studied patients

\begin{tabular}{|l|l|}
\hline & $\begin{array}{l}\text { The studied } \\
\text { population }(\mathrm{N}=30)\end{array}$ \\
\hline $\begin{array}{l}\text { Union time (weeks) } \\
\text { Mean } \pm \text { SD }\end{array}$ & $6.21 \pm 1.03$ \\
\hline $\begin{array}{l}\text { Extension deficit }\left(^{\circ}\right) \\
\begin{array}{l}\text { Mean } \pm \text { SD } \\
\text { (Range) }\end{array}\end{array}$ & $\begin{array}{l}5.06 \pm 2.87 \\
0-10\end{array}$ \\
\hline $\begin{array}{l}\text { Flexion }\left(^{\circ}\right) \\
\text { Mean } \pm \text { SD } \\
\text { (Range) }\end{array}$ & $\begin{array}{l}79.63 \pm 4.52 \\
70-90\end{array}$ \\
\hline
\end{tabular}

Table 5: Post-operative clinical characteristics of the studied patients

\begin{tabular}{|l|l|}
\hline & $\begin{array}{l}\text { The studied } \\
\text { population } \\
(\mathrm{N}=30)\end{array}$ \\
\hline \hline Excellent & $10(33.3 \%)$ \\
\hline Good & $16(53.3 \%)$ \\
\hline Fair & $3(10 \%)$ \\
\hline Poor & $1(3.3 \%)$ \\
\hline
\end{tabular}

Table 6: Outcomes of the studied patients according to Crawford's criteria

\begin{tabular}{|l|l|}
\hline & $\begin{array}{l}\text { The studied } \\
\text { population }(\mathrm{N}=30)\end{array}$ \\
\hline \hline Superficial infection & $3(10 \%)$ \\
\hline Skin necrosis & $1(3.3 \%)$ \\
\hline \hline Pin track infection & $1(3.3 \%)$ \\
\hline
\end{tabular}

Table 7: Complications distribution of the studied patients

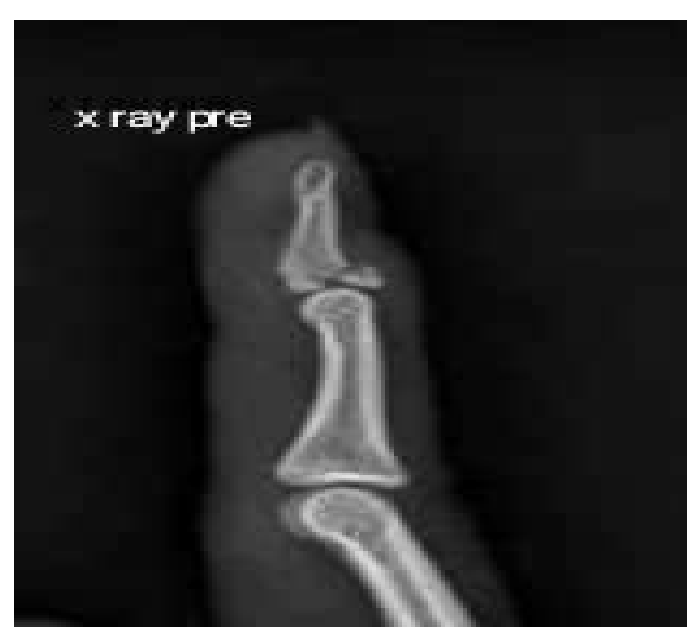

Orthopedic Surgery
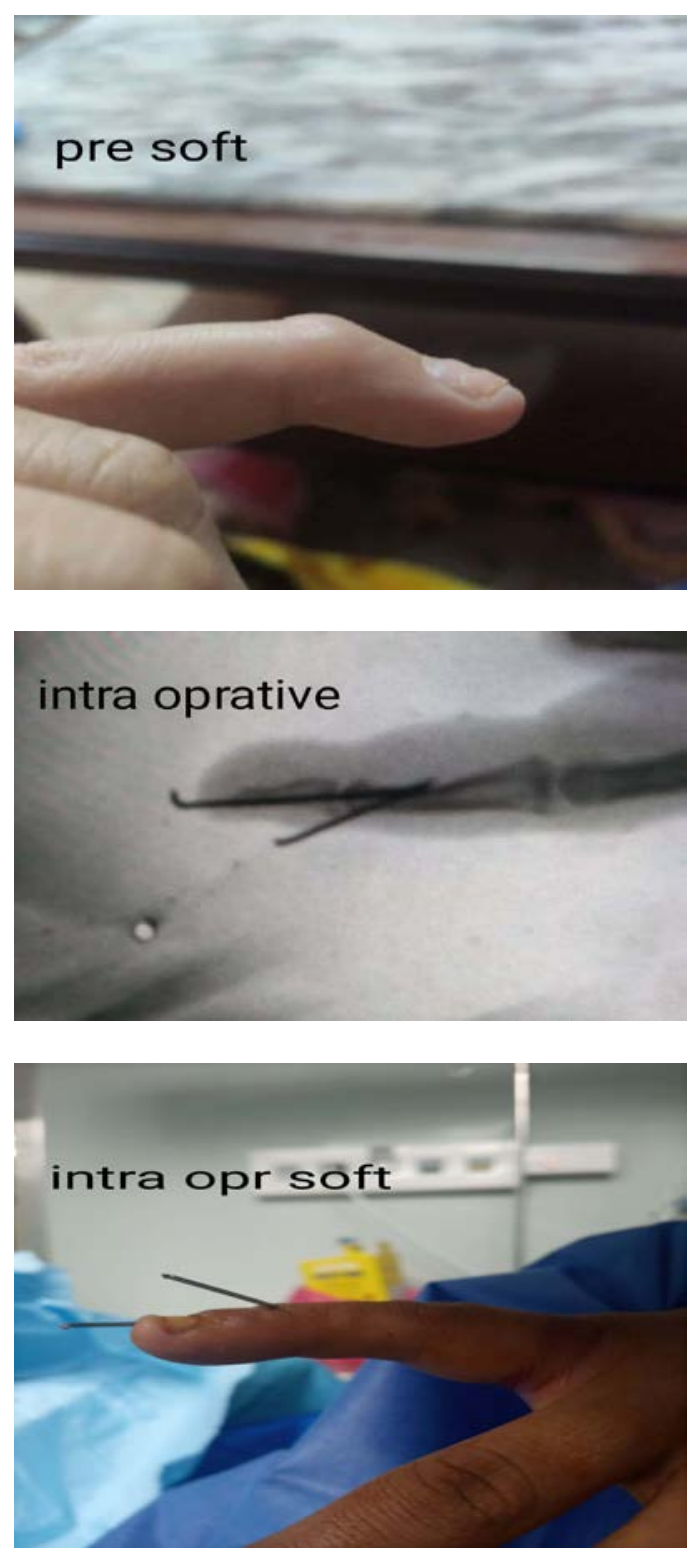

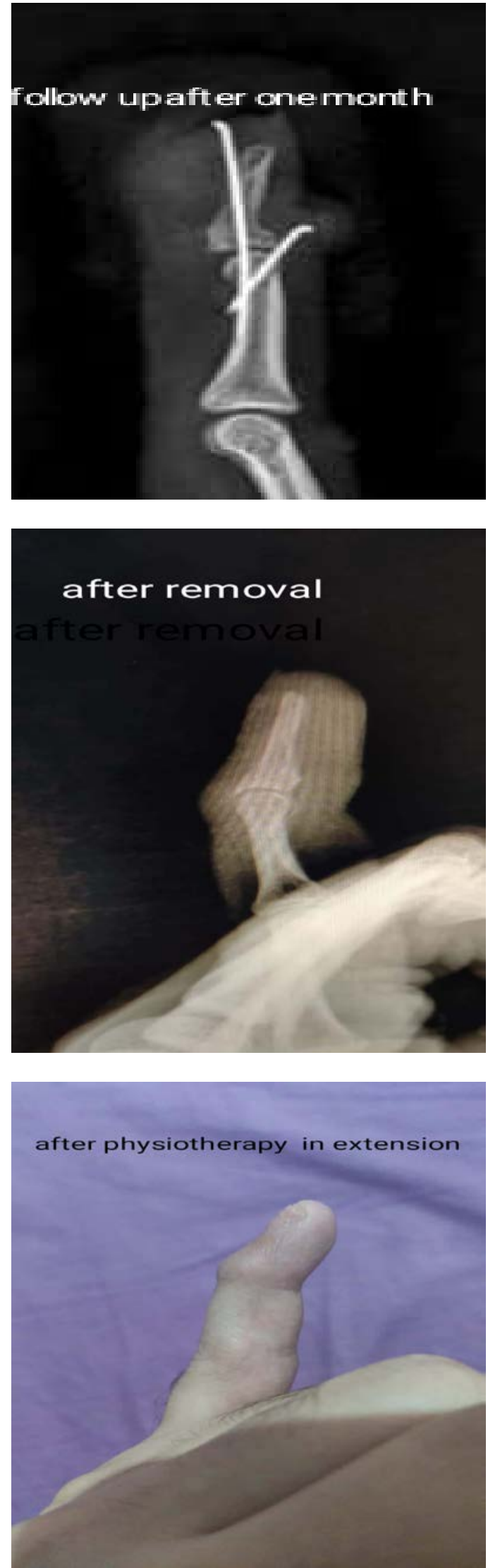

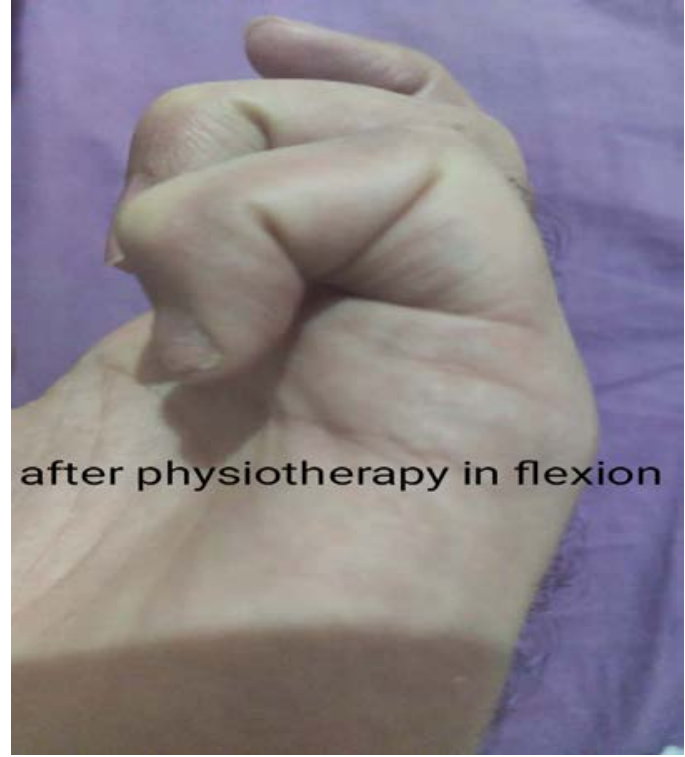

\section{DISCUSSION}

Mallet finger is one of the most frequent fingertip injuries that is made by trauma to the terminal inserting of the extensor digitorum tendons. It frequently happens throughout sport activity, while it could as well happen throughout every day activity. Mallet fractures can be associated with soft tissues injuries of the extensor digitorum tendons or avulsion fractures of the distal phalanx. ${ }^{8}$

This is the reason of the study selection to be performed to assess the outcomes of the extension block fixation procedure that was defined initially by Ishiguro.

This prospective random trial that was performed on 30 -cases of either sex and of ages ranging between 20 and 50-yrs old, the current work was performed in orthopedic Surgery departments in Al-Azhar University (Cairo). The duration of the stud

The age of the patients ranges 22 - 50-yrs with mean 44.67 -yrs, the majority of patients were males by $60 \%$.

Our findings were approved by results of Jain et al., ${ }^{9}$ who concluded that the demographic data found an age average of 33.3-yrs in their sample size with 13men and 6-women.

Furthermore, Han et al., ${ }^{10}$ demonstrated that a number of 41-cases (29-men and 12-women) have involved in the current work, with ages mean of 36yrs (between, 15 and 62-yrs).

The present study showed that $50 \%$ of the patients came in less than a week since fracture, $30 \%$ of the patients came in the same day of the fracture while $20 \%$ of the patients came after a week. Right side was the fractured in $70 \%$ of the patients while the left was $30 \%$. The predominant mechanism of the injury in $46.7 \%$ of patients was fall, $36.7 \%$ were sport and $16.7 \%$ were work accident.

Our results were in line with study of Çapkın et al., ${ }^{11}$ as they reported that 8-fractures were in right and five were in the left hand, with the ring-finger was 
the most frequently influenced (6-patients), then the little-finger (4-patients), middle-finger (2-patients) and index-finger (1-patient). The injury reasons were a falling (7 -patients), sports injuries (3-patients), occupational accidents (2-patients) and a fighting (1patient). The mean time from the injury to surgical operation was 3.3 days.

In the study of Jain et al., ${ }^{9}$ the majority of the cases, 12 out of the 19 were a result of non-sports related trauma. The digits involved were 4 index-fingers, ${ }^{11}$ middle-finger, 3 ring-fingers and 1 little-finger.

The current study showed that IIB was the predominant classification in $63.3 \%$ of the patients, IIC was found in $26.7 \%$, IB was found in $6.7 \%$ and only one patient was IC.

Also, in the investigation of Han et al., ${ }^{10}$ regarding the W-S sorting, 23-patients were type-IB, 2-patients were type-IIA, 14-patients were type-IIB, and 2patients were type-IIC. And no patients of types-IC or III were found.

Also, Ricardo, ${ }^{12}$ demonstrated that in accordance to Wehbe' \& Schneider's sorting, there were 6-patients of type-IB, and 4-patients of type-IIB fractures.

In the study in our hands, the mean operative time was $35.72 \pm 10.09 \mathrm{~min}$ and mean hospital time $1.19 \pm$ 0.349 day. The mean union time was $6.21 \pm 1.03$ weeks. The mean extension deficit was $5.06 \pm 2.87^{\circ}$. The mean flexion was $79.63 \pm 4.52^{\circ}$.

Our findings were approved with the results by Çapkin et al., ${ }^{11}$ who concluded that the mean following-up interval was 8.2-mths (ranging between 4 and 12-mths), with all K-wires detached afterward 4-wks. But combination was not completed afterward 5-wks in 2-cases, so the orthoses were reserved till the end of $6^{\text {th }}$ week in these patients, meaning that total; the orthotic splints were employed for a mean of 5.1-wks. Radiographic bone combination has been attained by $5^{\text {th }}$ or $6^{\text {th }}$ week (mean of 5.1). At the ultimate following-up, the DIP has flexions average of 76.1-degrees (ranging from 65 to 80-degrees) and extension average shortage of 3.84-degrees (ranging from zero to 15 degrees).

Also, Jain et al., ${ }^{8}$ demonstrated that the average period of radiological union was 6.4 weeks. The average range of flexion attainted was $75.6 \mathrm{deg}$.

The current work revealed that 10-cases (33.3\%) have excellent outcome, 16-cases (53.3\%) have good outcome, 3-cases (10\%) have fair outcome and 1case (3.3\%) has poor outcome.

The present findings have been approved by results of Çapkın et al., ${ }^{11}$ who concluded that in accordance to Crawford's criteria, 8-cases have excellent outcomes, 4-cases have good outcomes, and 1-case has a fair outcome.

In the study of Ricardo, ${ }^{12}$ using the Crawford's assessment measures, 3-cases (3 fingers; 30\%) have excellent outcomes, 6 (60\%) have good outcomes, and one case $(10 \%)$ has fair outcomes. And no poor outcomes were found.
Also, Jain et al., ${ }^{8}$, revealed that the Crawford outcome classification was used to evaluate the postoperative functional outcome, according to which they obtained 11 excellent results, 4 good result and 4 fair outcomes.

The current study showed that regarding complications, $3(10 \%)$ patients have superficial infection; one (5.6\%) case has skin necrosis and one (5.6\%) patient have pin track infection. No patients reported complications, such as non-union, malunion, dislocation, osteomyelitis, osteoarthritis of DIP joint, nail deformities and dorsal tenderness.

Our results were in agreement with study of Çapkın et al., ${ }^{11}$ as they reported that no any complications were found, like the fracture fragmentation, nail deformation, volar subluxation, or dislocation or DIP joint osteoarthritis. 2-patients advanced surface infections, and one patient advanced skin necrosis; all of them were managed with oral anti-biotics and wound care, if required.

Also, infection at the pin track site, marginal skin necrosis and deformity of the nail may adversely affect the outcome as concluded by Bischoff et al., ${ }^{13}$ in their work.

In the study of Bhasme ${ }^{14}$ there were no infections of pin tracks or skin necrosis. The fracture had well united in all the patients on follow-up check radiograph. Osteoarthritis of the distal interphalangeal joints was not seen in any case at follow-up.

\section{CONCLUSION}

Extension block pinning is a simple and effective management modality for mallet fracture when performed correctly. It provides excellent functional outcome in acute and subacute presentations. It also gives the advantage of treating the fracture as a day care procedure with minimal instruments and no post-operative scars.

\section{REFERENCES}

1. Romano, N., Marino, M., Mussetto, I., et al. Dynamic HRUS of the extensor mechanism of the finger: normal anatomy and diseases. European Congress of Radiology; 2017.

2. Vazquez, Ana Benitez. "Assessing hand ligaments and tendons lesions using MRI." European Congress of Radiology, 2017.

3. Bachoura, Abdo, Alex J. Ferikes and John D. Lubahn. "A review of mallet finger and jersey finger injuries in the athlete." Current reviews in musculoskeletal medicine. 2017; 10(1):1-9.

4. Wieschhoff, Ged G., et al. "Traumatic finger injuries: what the orthopedic surgeon wants to know." RadioGraphics. 2016; 36(4): 1106-28. 
5. Kalainov, Okafor, Wehbe, et al., Complications of carpal tunnel release. Orthopedic Clinics. 2016; 47(2), 425-33.

6. Rozmaryn, Leo M. "Mallet Deformity." Fingertip Injuries: Diagnosis, Management and Reconstruction. 2015; 11.

7. Lin, J. S., \& Samora, J. B. Surgical and nonsurgical management of mallet finger: a systematic review. The Journal of hand surgery. 2018; 43(2): 146-63.

8. Bloom JMP, Khouri JS and Hammert WC Current concepts in the evaluation and treatment of mallet finger injury. Plast Reconstr Surg. 2013; 132(4):560e-6e.

9. Jain DK, Kumar A and Sugumar A, Anand V. Treatment of mallet fracture by extension block pinning. International Journal of Orthopaedics. 2017; 3(1): 05-8.
10. Han HH, Cho HJ, Kim SY, et al. Extension block and direct pinning methods for mallet fracture: A comparative study. Archives of plastic surgery. 2018; 45(4): 351.

11. Çapkın S, Buyuk AF, Sürücü $S$, et al. Extension-block pinning to treat bony mallet finger: Is a transfixation pin necessary?. Ulusal travma ve acil cerrahi dergisi= Turkish journal of trauma \& emergency surgery: TJTES. 2019; 25(3): 281-6.

12. Ricardo M. The extension block technique for the treatment of mallet finger fracture. Ortho \& Rheum Open Access J. 2016; 3(3): 555615.

13. Bischoff, R., Buechler, U., De Roche, R., et al. Clinical results of tension band fixation of avulsion fractures of the hand. The Journal of hand surgery. 1994; 19(6), 1019-1026.

14. Bhasme A.S. Extension Block K-Wire Technique in the Management of Mallet Finger. International Journal of Scientific Research, 2016. 